\title{
LONG-TERM STRENGTH OF A COMPOSITION OF COMPLEX REFRACTORY COATING AND SINGLE-CRYSTAL RHENIUM-ALLOYED NICKEL ALLOY AFTER HIGH-TEMPERATURE HOLDS
}

\author{
V. P. Kuznetsov, ${ }^{1,2}$ V. P. Lesnikov, ${ }^{1,2}$ E. V. Moroz, ${ }^{1}$ M. S. Khadyev, ${ }^{1}$ and I. P. Konakova ${ }^{1}$
}

Translated from Metallovedenie i Termicheskaya Obrabotka Metallov, No. 8, pp. 7 - 12, August, 2013.

\begin{abstract}
The long-term strength of a system of single-crystal nickel alloy ZhS36-VI with $\mathrm{Cr}-\mathrm{Al}$ gas circulation coating $(\mathrm{GCC})+\mathrm{Ni}-\mathrm{Cr}-\mathrm{Al}-\mathrm{Ta}-\mathrm{Re}-\mathrm{Y}$ ion-plasma coating (IPC) $+\mathrm{Al}-\mathrm{Ni}-\mathrm{Cr}-\mathrm{Y}$ ion-plasma coating (IPC) is analyzed under conditions close to the operating ones after a hold for $1-1000 \mathrm{~h}$ in a temperature range of $1050-1300^{\circ} \mathrm{C}$
\end{abstract}

Key words: single-crystal refractory nickel alloy, refractory coatings, phase composition, properties.

\section{INTRODUCTION}

Joint action of a high-temperature oxidizing environment and stresses cause coagulation and partial dissolution of $\gamma^{\prime}$-phase and formation of a great number of surface cracks in refractory nickel alloys. Such processes give rise to softening and final failure of the alloys. The time before failure is shortened quite substantially.

Failure of refractory nickel alloys upon contact with an oxidizing environment starts from the surface. This makes application of nickel-base alloys impossible without protective coatings. Today the main tendency in advancement of protective coatings for rotor vanes of aircraft gas turbine engines (GTE) from refractory nickel alloys is to pass from single-layer aluminide coatings to multilayer ones [1 - 3].

In our earlier works we have studied the structure and phase composition of a complex diffusion-condensation $\mathrm{Cr}-\mathrm{Al} \mathrm{GCC}+\mathrm{Ni}-\mathrm{Cr}-\mathrm{Al}-\mathrm{Ta}-\mathrm{Re}-\mathrm{Y} \mathrm{IPC}+\mathrm{Al}-\mathrm{Ni}-$ $\mathrm{Cr}-\mathrm{Y}$ IPC protective coating and the reaction zone of its interaction with single-crystal alloy ZhS30-VI after high-temperature holds at $1050-1300^{\circ} \mathrm{C}$ for $1-1000 \mathrm{~h}$ [4].

The aim of the present work was to study the effect of a complex $\mathrm{Cr}-\mathrm{Al} \mathrm{GCC}+\mathrm{Ni}-\mathrm{Cr}-\mathrm{Al}-\mathrm{Ta}-\mathrm{Re}-\mathrm{Y} \mathrm{IPC}+$ $\mathrm{Al}-\mathrm{Ni}-\mathrm{Cr}-\mathrm{Y}$ IPC coating on long-term strength of single-crystal alloy $\mathrm{ZhS30-VI} \mathrm{[001]} \mathrm{after} \mathrm{high-temperature}$ holds at $1050-1300^{\circ} \mathrm{C}$ for $1-1000 \mathrm{~h}$.

1 Ural State Federal University in the Name of the First President of Russia B. N. Eltsyn, Ekaterinburg, Russia.

2 "Turbomet" Company, Ekaterinburg, Russia (e-mail: turbomet@e1.ru).

\section{METHODS OF STUDY}

We studied specimens with single-crystal structure fabricated from refractory nickel alloy $\mathrm{ZhS36-VI}$ with a $\mathrm{Cr}-\mathrm{Al}$ $\mathrm{GCC}+\mathrm{Ni}-\mathrm{Cr}-\mathrm{Al}-\mathrm{Ta}-\mathrm{Re}-\mathrm{Y} \mathrm{IPC}+\mathrm{Al}-\mathrm{Ni}-\mathrm{Cr}-\mathrm{Y}$ IPC protective coating after a standard heat treatment. The average chemical composition of alloy ZhS36-VI, the mode of its heat treatment, and the process of deposition of protective coatings on the castings have been described earlier in [4]. The total thickness of the complex coating on all the specimens in the initial state was about $80-90 \mu \mathrm{m}$.

Since the distribution of temperatures over the surface of a turbine vane feather is nonuniform, the service life of the vane is determined by the operating capacity of the "refractory nickel alloy - coating" composition in "hot" zones of the vane with maximum surface temperature. We subjected specimens of alloy ZhS-36-VI with a complex protective coating to high-temperature holds for $1-1000 \mathrm{~h}$ in a range of $1050-1300^{\circ} \mathrm{C}$ in the furnace air atmosphere.

The tests for long-term strength were performed at a stress of $340 \mathrm{MPa}$ at $975^{\circ} \mathrm{C}$ in the air atmosphere of the furnace in a VPK-11 machine under uniaxial loading for cylindrical specimens with functional part $5 \mathrm{~mm}$ in diameter and $25 \mathrm{~mm}$ long. The specimens were cut from cast billets $14 \mathrm{~mm}$ in diameter subjected to high-temperature holds by different regimes.

The structure, and the phase and chemical composition of the alloy and of the protective coatings were studied with the help of a computer-aided "Neophot-32" light microscope, a "Phillips SEM 535"scanning electron microscope 


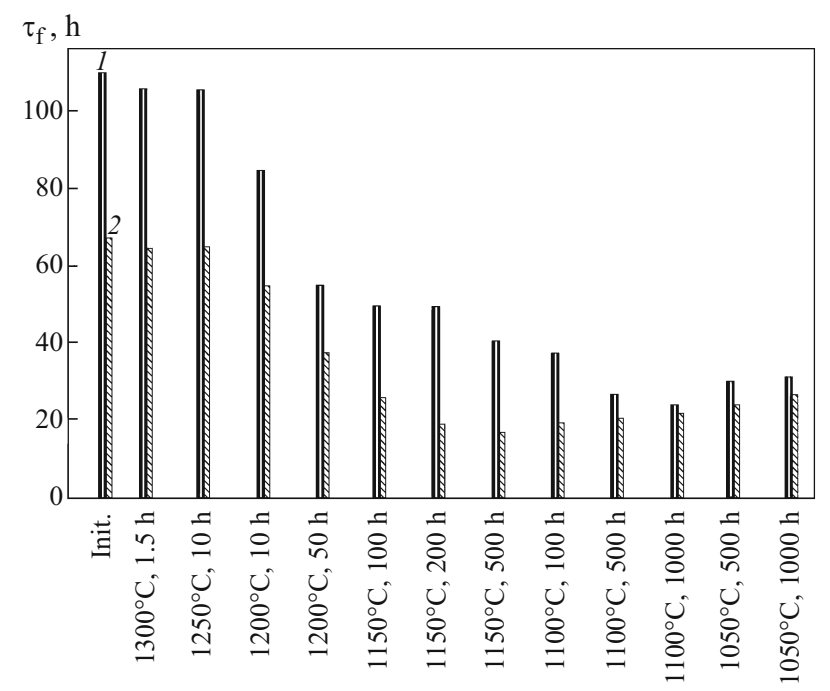

Fig. 1. Endurance of alloy ZhS36-VI [001] (tested at $340 \mathrm{MPa}$ and $975^{\circ} \mathrm{C}, \tau_{\mathrm{f}}$ is the time before failure) after high-temperature holds by different regimes for specimens with (1) and without (2) protective coating.

with a "EDAXGenesis 2000 SUTV" attachment for microanalysis, and a JEOL JSM-6490LV device. The electron microscope studies were performed by the method of diffraction electron microscopy of thin foils using an EMV 100L electron microscope. The foils were prepared as in work [5].
A "SIAMS-600" image analyzer was used to determine the volume fraction of the topologically close-packed (tcp) phases in dendrite arms of alloy ZhS36-VI after high-temperature holds and tests for long-term strength. The software permits determination of the fractions of black and white areas on an electron image of microstructure. A color electron image is converted into a binary one, where the black field corresponds to the $\gamma / \gamma^{\prime}$ phase and the white field corresponds to segregations of tcp phases.

\section{RESULTS AND DISCUSSION}

To study the effect of the complex $\mathrm{Cr}-\mathrm{Al} \mathrm{GCC}+\mathrm{Ni}-$ $\mathrm{Cr}-\mathrm{Al}-\mathrm{Ta}-\mathrm{Re}-\mathrm{Y}$ IPC $+\mathrm{Al}-\mathrm{Ni}-\mathrm{Cr}-\mathrm{Y}$ IPC coating on the long-term strength of alloy $\mathrm{ZhS36-VI}$ we tested coated and uncoated specimens after high-temperature holds. The results of these tests are presented in Fig. 1. It can be seen that the endurance of alloy ZhS36-VI with the complex coating is $20-30 \%$ higher than that of the uncoated alloy (Fig. 1). The positive action of the coating on the long-tern strength of alloy ZhS36-VI is intensified upon growth in the temperature and time of the holds.

The structure of alloy ZhS36-VI [001] without protective coating is presented in Fig. $2 a$ and $b$. After a standard heat treatment of the alloy the nonequilibrium $\left(\gamma+\gamma_{\text {eu }}^{\prime}\right)$ eutectic dissolves in the arm spacing, which is accompanied by for-
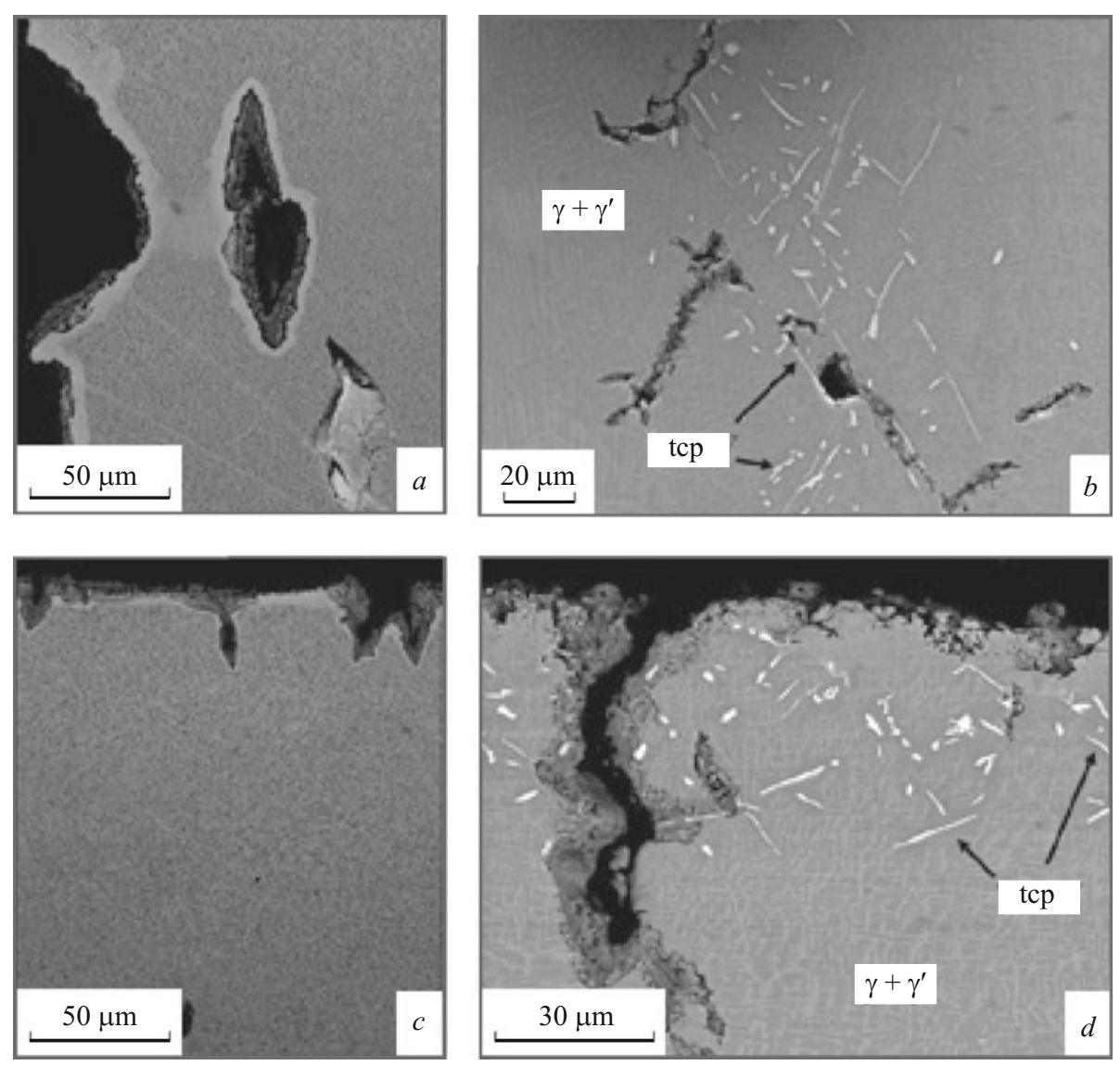

Fig. 2. Structure of alloy ZhS36-VI [001] without protective coating (cross section) after testing for long-term strength (tcp is a topologically close-packed phase): $a, b$ ) after a standard heat treatment; $c, d$ ) after a 500-h hold at $1100^{\circ} \mathrm{C} ; a, c$ ) matrix metal; $b$, d) surface layer. 
mation of spherical homogenization micropores. During the tests of the alloy for longterm strength these micropores grow, acquire the shape of an ellipse extended over the stress axis, and serve places of nucleation of microcracks (Fig. $2 a$ ). When creep develops, these microcracks propagate perpendicularly to the applied stress [6].

After the holds at $1050-1200^{\circ} \mathrm{C}$ for $100-1000 \mathrm{~h}$ the metal fractures over segregations of the tcp-phase (see Figs. $2 c$ and $d)$. The tcp-phase is enriched with the refractory elements of the alloy, which causes depletion of the $\gamma$-solid solution with respect to Re, W and Mo and lowers the sliding resistance of dislocations in the $\gamma$-phase. The segregations of the tcp-phase are stress concentrators and places of nucleation of microcracks. The tcp segregations are surrounded by a $\gamma^{\prime}$-phase, and cracks grow over the $\gamma^{\prime}$-phase/tcp-phase boundary causing failure of the specimens. When the specimens without coating are tested for long-
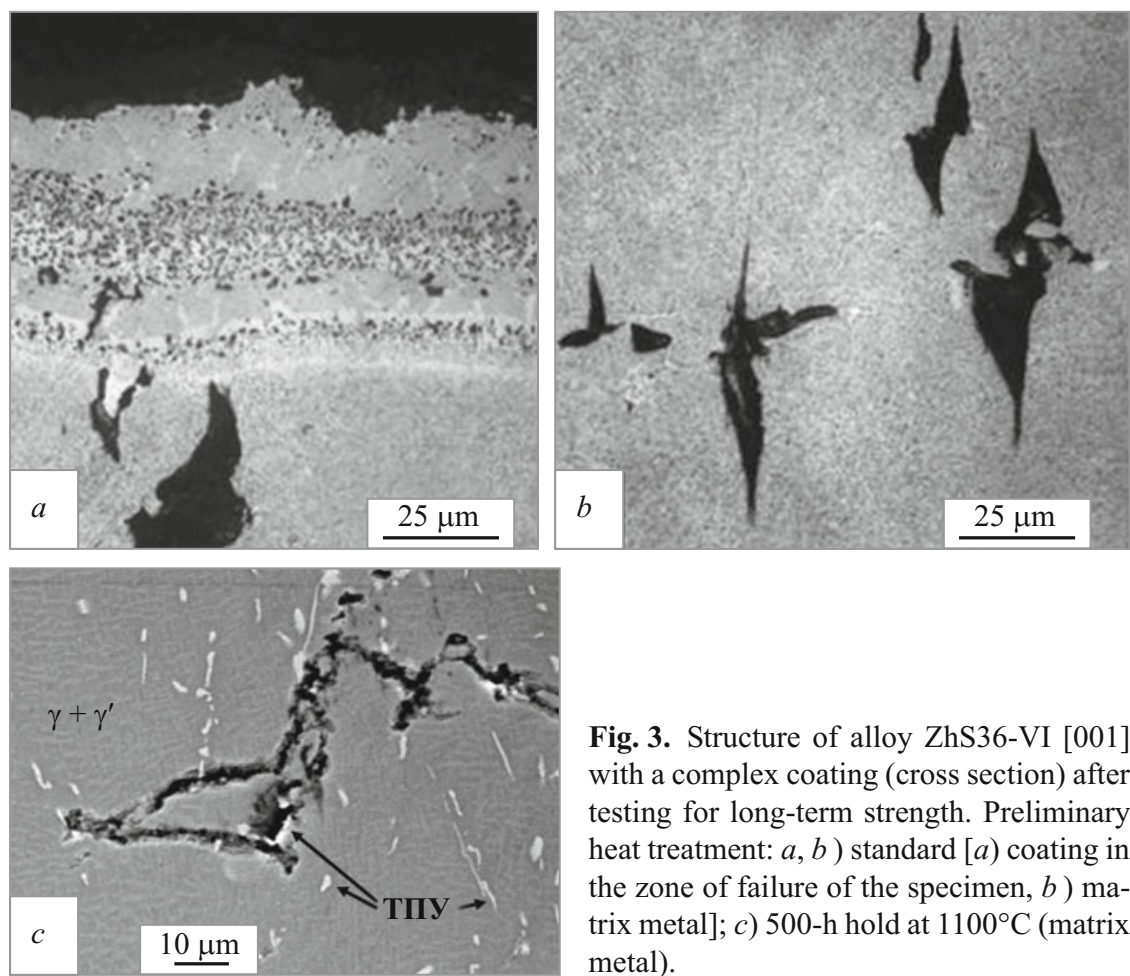

Fig. 3. Structure of alloy ZhS36-VI [001] with a complex coating (cross section) after testing for long-term strength. Preliminary heat treatment: $a, b)$ standard $[a$ ) coating in the zone of failure of the specimen, $b$ ) matrix metal]; c) 500 -h hold at $1100^{\circ} \mathrm{C}$ (matrix metal). term strength, their surface is oxidized. Microcracks form in the changed surface layer of the $\gamma$-phase (Fig. $2 b$ and $d$ ) and propagate into the matrix metal (alloy ZhS36-VI). This lowers the long-term strength and is the decisive mechanism of failure of the specimens in the stage of accelerated creep.

In the specimens of alloy ZhS36-VI with protective coating microcracks also arise in long-term tests and propagate over the tcp-segregations. The complex coating hinders the high-temperature oxidation of the alloy and decelerates the development of microcracks on the surface of the specimens (Figs. 3 and 4), i.e., raises considerably the operating capacity and the endurance of the single-crystal ZhS-36-VI.

The diffusion processes occurring in high-temperature holds at $1050-1250^{\circ} \mathrm{C}$ yield a secondary reaction zone

(SRZ) on the "alloy ZhS36-VI [001] - diffusion zone" interface $[4,7]$; the reaction zone has a three-phase $\gamma-\gamma^{\prime}$ tcp-phase structure. The SRZ grows from the diffusion zone of the coating into the depth of the alloy. The matrix of the SRZ is a coarse $\gamma^{\prime}$-phase containing segregations of a tcp-phase. Prolongation of high-temperature holds causes growth of the SRZ and coarsening of the tcp-phases. Transition from an acicular (lamellar) shape of the tcp-phase to a lumpy and round shape develops in the direction from the matrix metal to the coating (Fig. 4). At a temperature above $1250^{\circ} \mathrm{C}$ (the start of intense growth of the $\gamma^{\prime}$-phase in the alloy) a SRZ does not form under the coating, and the tcp-phases coagulate and expand in the diffusion zone of the coating.
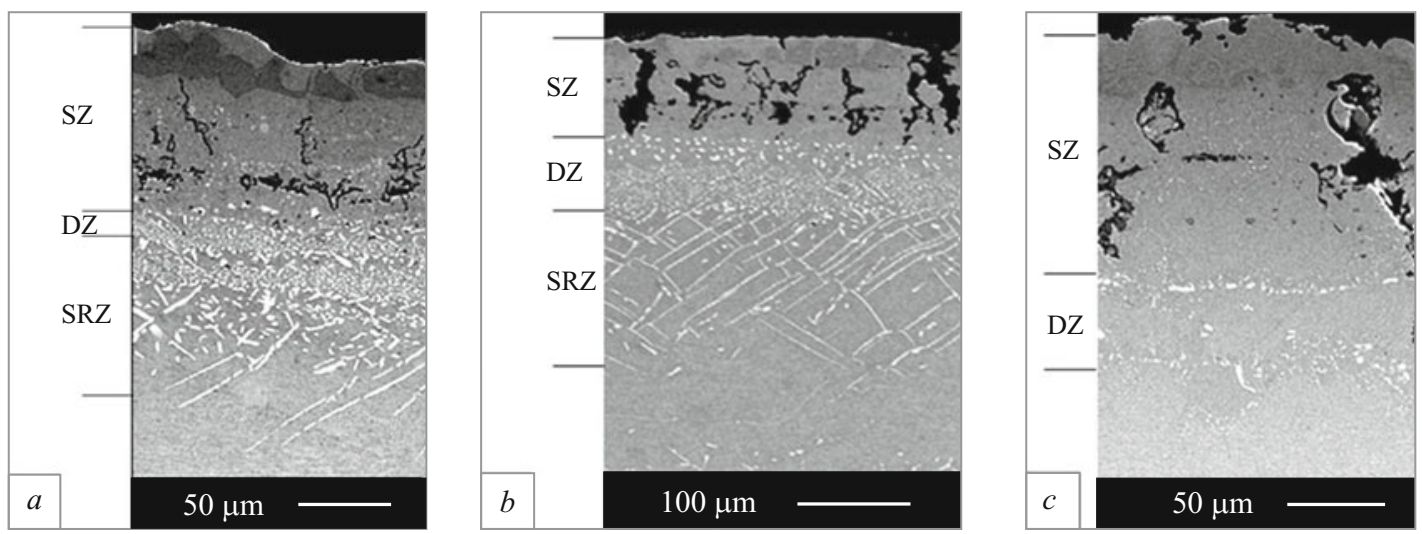

Fig. 4. Microstructure of alloy ZhS36-VI [001] with a complex coating after a high-temperature hold at $1050^{\circ} \mathrm{C}$ for $1000 \mathrm{~h}(a)$, at $1100^{\circ} \mathrm{C}$ for $1000 \mathrm{~h}(b)$, at $1200^{\circ} \mathrm{C}$ for $50 \mathrm{~h}(c)$ and testing for long-term strength. 

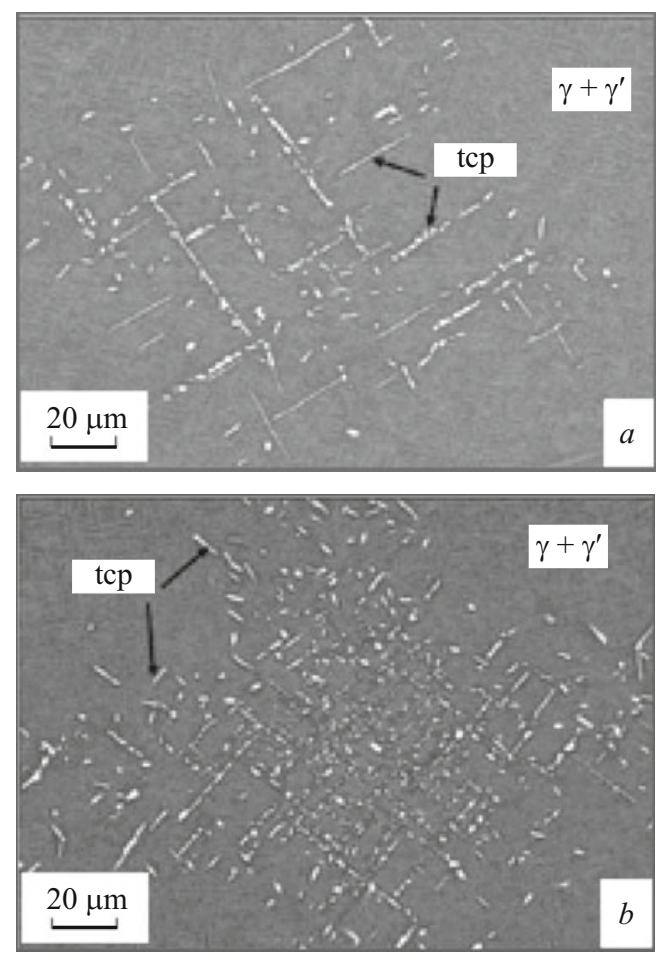

Fig. 5. Tcp-phase in arms of a dendrite cell of alloy ZhS36-VI [001] after hold at $1100^{\circ} \mathrm{C}$ for $500 \mathrm{~h}(a)$ and at $1150^{\circ} \mathrm{C}$ for $500 \mathrm{~h}(b)$. SEM.

The structural transformations on the "coating - matrix metal" interface depend primarily on the composition of the alloy and on the alloying elements in the $\gamma$ - and $\gamma^{\prime}$-phases. The wavy pattern of the front of growth of the "SRZ - matrix metal" interface is connected with the segregation inhomogeneity of the alloy in the dendrite arms and arm spacing. The growth of the thickness of the SRZ obeys a parabolic law, which is a sign of diffusion nature of its formation.

We established that the volume fraction of the tcp-phase segregated in the arms of dendrites during a high-temperature hold affects the long-term strength of alloy ZhS36-VI. We computed the arithmetic mean of the content of tcp-phase for the data of measurement at 10 points with a size of $100 \times 100 \mu \mathrm{m}$ lying in the arms of a dendrite cell (Fig. 6). The fraction of the tcp-phase turned out to be independent of the presence or absence of coating on the specimens. The volume fraction of the tcp-phase in the structure of alloy $\mathrm{ZhS36-VI} \mathrm{is} \mathrm{determined} \mathrm{primarily} \mathrm{by} \mathrm{the} \mathrm{processes} \mathrm{of} \mathrm{diffu-}$ sion of $\mathrm{W}, \mathrm{Re}, \mathrm{Mo}$ and $\mathrm{Cr}$ in the $\gamma$-solid solution and of $\mathrm{Al}$, $\mathrm{Ti}, \mathrm{Nb}$ in the $\gamma^{\prime}$-phase, as well as by the rate of formation of nuclei of the tcp-phase.

For long high-temperature holds the stability of the microstructure of refractory alloys is an important factor determining their mechanical properties in operation. We analyzed the fine structure of alloy ZhS36-VI with a complex coating after high-temperature holds and tests for long-term strength (Fig. 7).

The microstructure of single-crystal ZhS36-VI after a standard heat treatment is represented by two phases, i.e., a

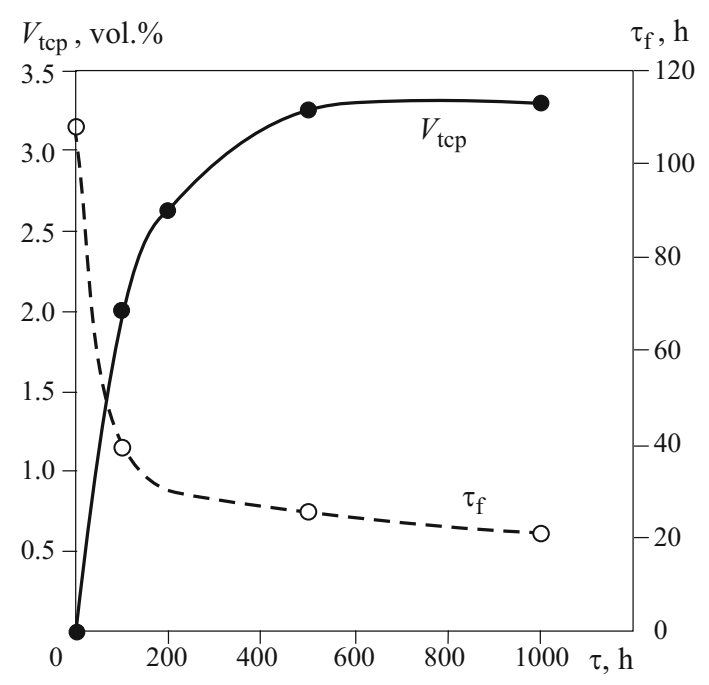

Fig. 6. Volume fraction of tep-phase $V_{\text {tcp }}$ in the arm of a dendrite cell and time before failure $\tau_{\mathrm{f}}$ in tests of coated alloy ZhS36-VI [001] for long-term strength as a function of the duration of preliminary hold at $1100^{\circ} \mathrm{C}$.

$\gamma$-matrix and cubic segregations of a hardening $\gamma^{\prime}$-phase $\left(\mathrm{Ni}_{3} \mathrm{Al}\right)$. In the tests of specimens in the initial condition (after a standard heat treatment) for long-term strength we observe merging of particles the $\gamma^{\prime}$-phase and formation of a raft structure; dislocation nets occur on the $\gamma / \gamma^{\prime}$ interface. In this condition the alloy possesses the highest long-term strength, because the raft structure is a barrier for displacement of dislocations and development of creep [8-10].

In long-term holds at $1050-1200^{\circ} \mathrm{C}$ the $\gamma^{\prime}$-phase looses its cuboid pattern, coagulates, and grows intensely in the direction perpendicular to [001] (Fig. 7). The driving force of such a change in the morphology of the $\gamma / \gamma^{\prime}$ structure of the alloy is mismatch between the lattice parameters and the moduli of elasticity of the $\gamma$ - and $\gamma^{\prime}$-phases. The layers of the $\gamma$-solid solution grow too. A special feature of the structure of alloy ZhS36-VI [001] after long holds at $1050-1200^{\circ} \mathrm{C}$ is the formation of tcp-phases with different morphologies (Fig. $7 b$ and $e$ ). Deciphering of electron diffraction patterns has shown that these tcp phases are a $\mu$-phase of type $(\mathrm{Ni}, \mathrm{Co})_{7}(\mathrm{Cr}, \mathrm{W}, \mathrm{Re}, \mathrm{Mo})_{6}$ with different morphologies and have the following approximate chemical composition (in wt.\%): $23 \mathrm{Ni}, 8 \mathrm{Co}, 40 \mathrm{~W}, 20 \mathrm{Re}, 4 \mathrm{Mo}$, and $5 \mathrm{Cr}$. Intense formation of $\gamma$-phase occurs in the arms of dendrite cells; they are enriched with the $\gamma$-forming elements of the alloy (Re, W, Co, Mo, Cr) and surrounded by a shell from $\gamma^{\prime}$-phase. Coarsening of the $\gamma / \gamma^{\prime}$-structure, segregation of $\gamma$-phases and, as a consequence, depletion of the $\gamma$-matrix with respect to Re and $\mathrm{W}$ result in decrease in the long-term strength of the alloy. The long-term strength of alloy $\mathrm{ZhS36-VI} \mathrm{is} \mathrm{correlated} \mathrm{to} \mathrm{the} \mathrm{content} \mathrm{of} \mathrm{the} \mathrm{formed} \mu$-phases (Fig. 6).

High-temperature holds at $1050-1100^{\circ} \mathrm{C}$ for $500-$ $1000 \mathrm{~h}$ give rise to nets of epitaxial dislocations on the $\gamma / \gamma^{\prime}$ 
Fig. 7. Fine structure of alloy ZhS36-VI [001] after high-temperature holds at $1050^{\circ} \mathrm{C}$ for $500 \mathrm{~h}(a-c)$ and at $1100^{\circ} \mathrm{C}$ for $500 \mathrm{~h}$ $(d-f)$ and testing for long-term strength: $a, d) \gamma / \gamma^{\prime}$ raft-structure; $\left.b, c\right) \mu$-phase against the background of $\gamma^{\prime}$-phase and microdiffraction from the encircled region with deciphering, respectively; $e, f$ ) lamellar tcp-phase against the background of homogeneous $\gamma^{\prime}$-phase and microdiffraction from the encircled region with deciphering, respectively.
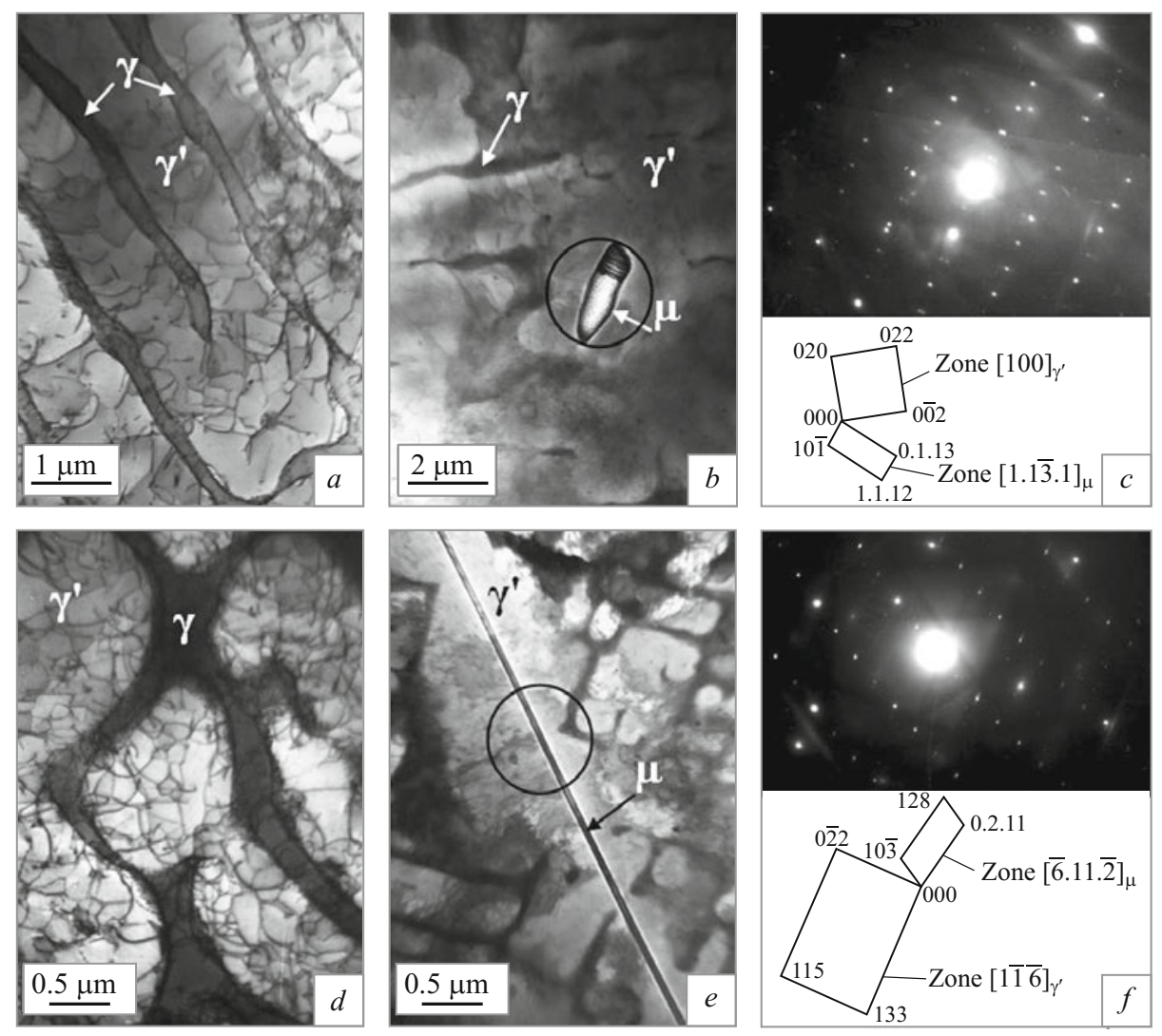

interface and in the solid solution (the $\gamma$-phase), which is a sign of considerable softening of particles of the $\gamma^{\prime}$-phase (Fig. $7 a$ and $d$ ). Numerous segregations of tcp-phases surrounded by phase $\gamma^{\prime}$ are encountered. The long-term strength of the "alloy - complex coating" composition is the lowest after the hold mentioned but exceeds that of the uncoated alloy (Fig. 1).

A hold at $1150^{\circ} \mathrm{C}$ for $100-500 \mathrm{~h}$ results in coagulation of the $\gamma^{\prime}$-phase and formation of secondary phases, just as after a hold for $500-1000 \mathrm{~h}$. The long-term strength of the "alloy - complex coating" composition meets the standardized values for alloy $\mathrm{ZhS36-VI}$.

A hold at $1200-1300^{\circ} \mathrm{C}$ for $1.5-50 \mathrm{~h}$ causes dissolution of the $\gamma^{\prime}$-phase; subsequent air cooling results in segregation of new hardening particles of $\gamma^{\prime}$-phase. After such a treatment the structure of the alloy resembles its structure after incomplete homogenization and cooling in air. No tcp-phase has been detected. The endurance of the alloy is somewhat lower than in the initial state.

\section{CONCLUSIONS}

1. The main feature of the structure of alloy ZhS36-VI after long-term high-temperature holds is the formation of tcp-phases with different morphologies, which have the following chemical composition (in wt. \%): $23 \mathrm{Ni}, 8 \mathrm{Co}, 40 \mathrm{~W}$, $20 \mathrm{Re}, 4 \mathrm{Mo}$, and $5 \mathrm{Cr}$. Intense formation of these phases oc- curs in the arms of dendrite cells; they are surrounded by a shell from $\gamma^{\prime}$-phase.

2. Coarsening of the $\gamma / \gamma^{\prime}$-structure, segregation of $\gamma$-phases and, as a consequence, depletion of the $\gamma$-matrix with respect to Re and $\mathrm{W}$ result in lowering of the long-term strength of the alloy. The long-term strength of alloy $\mathrm{ZhS36-VI}$ is correlated to the content of the formed $\mu$-phases.

3. The structural transformations on the interface of the matrix metal (alloy ZhS36-VI with $\gamma / \gamma^{\prime}$-structure) and the diffusion zone of the complex coating cause the appearance and growth of a secondary reaction zone during high-temperature holds; the zone has a three-phase $\gamma-\gamma^{\prime}-\mu$ structure.

4. The time before failure of alloy $\mathrm{ZhS36-VI} \mathrm{with} \mathrm{a} \mathrm{com-}$ plex $\mathrm{Cr}-\mathrm{Al} \mathrm{GCC}+\mathrm{Ni}-\mathrm{Cr}-\mathrm{Al}-\mathrm{Ta}-\mathrm{Re}-\mathrm{Y} \mathrm{IPC}+\mathrm{Al}-$ $\mathrm{Ni}-\mathrm{Cr}-\mathrm{Y}$ IPC coating tested for long-term strength is $25-30 \%$ longer than that of the alloy without coating, despite the formation of a secondary reaction zone under the coating.

\section{REFERENCES}

1. V. P. Kuznetsov, V. P. Lesnikov, S. A. Muboyadzhyan, et al., "Gradient complex protective coatings for single-crystal turbine blades of heat-stressed GTE," Metalloved. Term. Obrab. Met., No. 5(623), 41 - 48 (2007).

2. S. A Muboyadzhyan, V. P. Lesnikov, and V. P. Kuznetsov, Complex Protective Coatings for Turbine Vanes of Aircraft GTE [in Russian], Izd. "Kvist," Ekaterinburg (2008), 2008 p. 
3. S. A. Budinovskii, S. A. Muboyadzhyan, A. M. Gayamov, et al., "Development and investigation of combined refractory ion-plasma coatings for refractory nickel alloys with rhenium additive," Aviats. Mater. Tekhnol., No. 3, 3-12 (2008).

4. V. P. Kuznetsov, V. P. Lesnikov, I. P. Konakova, et al., "Structure and phase composition of a complex refractory coating and the reaction zone of interaction with single-crystal alloy ZhS36-VI after high-temperature holds," Metalloved. Term. Obrab. Met., No. 4, 36-41 (2013).

5. E. V. Moroz, "An electron microscope study of the fine structure of refractory nickel alloys," in: Proc. Int. Sci.-Eng. Conf. "Aspects of Aircraft Materials Science" [in Russian], FGUP "VIAM GNTS RF, Moscow (2007), p. 159.

6. V. P. Kuznetsov, V. P. Lesnikov, E. V. Moroz, et al., "Mechanical properties of refractory nickel alloy ZhS36VI for single-crystal of HPT blades," Metalloved. Term. Obrab. Met., No. 5(635), $23-26$ (2008).

7. S. A. Budinovskii, S. A. Muboyadzhyan, A. M. Gayamov, et al., "Ion-plasma refractory coatings with composite barrier layer for protecting alloy ZhS36VI from oxidation," Metalloved. Term. Obrab. Met., No. 1(667), 34 - 40 (2011).

8. R. E. Shalin, I. L. Svetlov, E. B. Kachanov, et al., Single Crystals of Nickel Refractory Alloys [in Russian], Mashinostroenie, Moscow (1997), $336 \mathrm{p}$

9. A. I. Epishin, "Stability of microstructure of refractory nickel alloys CMSX-4 and CMSX-10 under high-temperature creep," Materialovedenie, No. 1, 49 - 56 (2007).

10. V. P. Kuznetsov, V. P. Lesnikov, E. V. Moroz, et al., "Structure of refractory nickel alloy ZhS36VI for single-crystal HPT blades," Metalloved. Term. Obrab. Met., No. 4(634), 26 - 29 (2008). 